\title{
An Application of Integration (GBOM \& GPS) for Quick Response Manufacturing
}

\author{
Akela M. Al-Atroshi \\ Technical Institutel \\ Mosul
}

\section{Received on: 16/03/2009}

College of Computer Sciences

and Mathematics

University of Mosul

The current paper aims at treating a fundamental problem which is the large volume of operating data associated with increasing the variety, high competition and production according to (Quick Response Manufacturing ) system .Thus, the current study focuses on link the Generic Bill of Material file (GBOM) and Generic Product Structure file (GPS) to creating ( BOMO) Approach as the main requirement for applying (QRM) system, because this approach contributes, to a high extent, in reducing deadlines of production by achieving the simultaneous timing in performing processes .

In order to fulfill the aims of the current study, a database is designed by using (Oracle ), then applied practically to a real product(a three-drawer desk). The results are exhibited within the framework of (BOMO) through the integration between (BOMO) and the (Routing) of the product .

Keywords: Data base, Oracle, Quick response manufacturing.

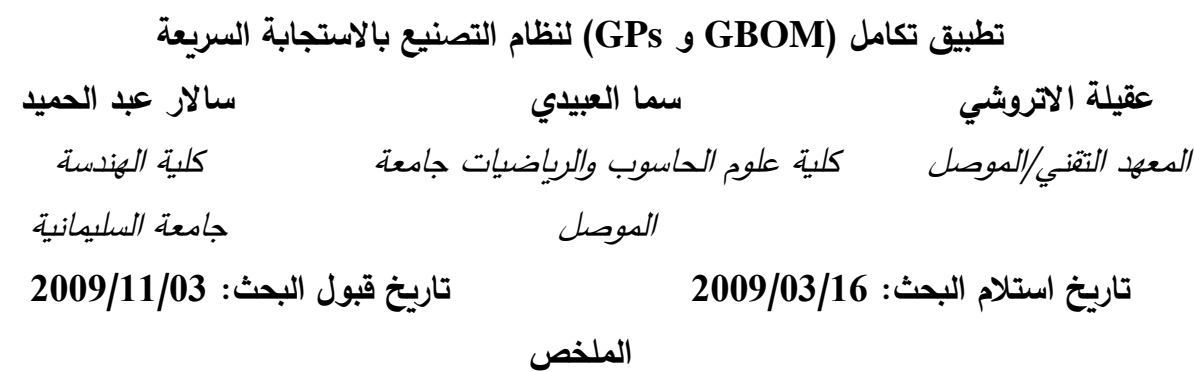

يهدف البحث الحالي إلى معالجة مشكلة أساسية تتحور حول الكميات الكبيرة من البيانات التثغيلية

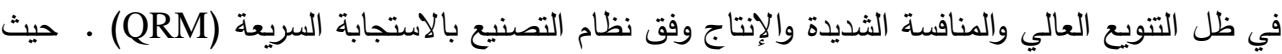

ركزت الدراسة على ربط ملف التركيبة الفنية (GBOM) وملف التركيبة العامة للمنتوج (GPS) لاستحداث

مدخل (BOMO) باعتباره أبرز المتطلبات التي رافقت تطبيق نظام التصنيع بالاستجابة السريعة. إذ يساهم

وعلى نحو كبير في تخفيض المهل الزمنية للمنتوج وذلك من خلال تحقيق التزامن في أداء العمليات.

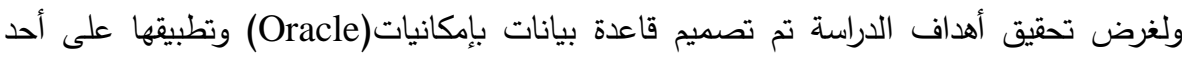

المنتوجات وهي منضدة مكتب وتم عرض نتائج التطبيق في إطار (BOMO) ومن خلال التكامل بين ملف تهن

التركيبة الفنية(GBOMO) وملف تركيبة فصيلة المنتوج.

الكلمات المفتاحية: قاعدة بيانات، اوراكل، نظام التصنيع بالاستجابة السريعة. 


\section{Problem description and Methodology}

Local and international communication networks contribute widely in applying the modern technologies to the modern manufacturing environment. These technologies include: competitive properties, high variety of the product, creating heterogeneous markets, dividing the markets and demands as well reducing the life cycle of the product. Thus, adopting production styles to take up the above properties became very urgent. Accordingly, the method of (Mass Customization) appeared and became applicable by using the (Quick Respond manufacturing system), within the framework of the (Agile Factory) (Suri, 1998).

In accordance with the wide spread use of (QRM), the latter witnessed drastic changes especially in the routines of implementing business activities electronically in industrial companies, specifically, adopting the ( General Bill Of Materials GBOM) and integrating it with the (GPS), which represents the spark of creation in modern manufacturing. Unfortunately this subject is of a high importance, yet, the Iraqi specialists and industrial companies do not pay it the adequate attention. For this reason, the main problem tackled in the current paper is that our industrial companies will loose the change of benefiting of this vital subject in improving their performance, unless these companies are enriched by theoretical and practical studies.

The importance of this study lies in using Bill of Materials and Operational (BOMO) as an ambitions treatment to control the production operations, and to deal with the abundant data resulting from the large variety of the products according to (QRM) system.

The Objective of the current paper are:

1. Following the changes and novelties which associate the (QRM) system, within the framework of the (Agile factory).

2. Suggesting a practical addition to the design of (BOMO) as part of the database designed by (Oracle), as well illustrating the mechanism which operates this design through the integration between (GBOM) and (GPS).

3. Preparing a (BOMO) diagram for a real product (a desk with three drawers).

So, before entering the subject of the research, its necessary to indicate the previous studies which tackled the topic of using (BOMO) as an adequate treatment to control the large variety of products are listed below:

1. (Jiao, 2000). This study tackled using the (BOMO) approach to treat the large variety in customization system. Depending on the concepts of the architecture of the product family and a relational model for data, the system of (Graph rewriting) is developed to support the 
design of the product family. The mentioned system is characterized by gathering different viewpoints of the (GBOM).

2. A collection of studies by ( Du et.al., 2001,2002,2005). These studies tackle the integration between the (Bill of Materials) and (Routing) for the operations in order to treat the large variety of products. These studies adopt the (Object-Oriented) technique for designing (BOMO).

Double checking the a bove studies reveals that all of them are carried out in the industrially advanced countries, specifically in the centers specialized in customer - driven production. Thus, the current study is considered a pioneer one and it is the first study, at least in Iraq, which illustrates the treatment logic in (BOMO) and uses (Oracle) facilities to design practical software that can be used and applied to a real case study product which is a three - drawer desk.

\section{Quick Response Manufacturing concept and Architecture}

Many references confirm that the (QRM) system depends basically on (Time Based Competitive (TBC)) Strategy, Whose main principles are to compete depending on speed obviously, The company which uses this strategy can deliver the product or the service faster than its rivals (Suri,2002,4;Turner,2006,20).

Quick response manufacturing requires flexibility and speed, especially when applied in an environment which constantly changes the amount of lab our, industrial operation and technologies to meet the demands of the customers .(Janis,1997:2).Usually,(QRM) is defined as: a thorough practical strategy which adopts an ideology aims at reducing the lead-time of the detailed activities of the administration ,the manufacturing methods and the analyzing technologies by following a program which depends on serial in order to achieve the desired reduction in lead time. (Tubino,2001:1).

The rules of (QRM) strategy are best applied in two types of firms: (Russell, 1998:34 ;Tubino,2001:1),

1. Those which manufacture products of which the operation procedures and designs are complicated ,from the engineering point of view. These companies also adopt the policy of small payments even if their products are unique in the market.

2. Those who do not re-design product which they But they have large of products which are highly demanded.

To deeply understand the concepts of (QRM) system , one must distinguish between the following definitions: (Suri,2002,3-4)

1. Externally context, as perceived by customers, QRM means responding to those customers' needs by rapidly designing and manufacturing products 
customized to those needs. QRM goes beyond the established goals and even the capabilities of lean manufacturing.

2. Internally context, in terms of a company's own operations, QRM focuses on reducing the times for all tasks in a company, resulting in improved quality, lower cost, and of course quick response .

QRM is a practical strategy: it embodies the mindset of pursuing lead time reduction, along with detailed management principles, manufacturing methods, analysis techniques and tools and a step methodology to achieve the desired reduction in lead times.

The main contributes in developing (QRM) system are the enormous developments in hardware, software and communication instruments ,which altogether aim at controlling, adequately ,the flow of information through the arranging borders of the virtual companies which cooperate to manufacture the product, depending on applying the strategy also provides the customer with the available information about the product or the service .It also enables the customer to provide the manufacturing company with his opinion and desire about the product (Evans,1997:126; Lindsay,2002:2).

Concerning the architecture of the system ,one can refer to (Pine) who points out that (QRM) is considered one of the best approaches to the (Mass Customization) philosophy .Fig (1) illustrates the architecture of (QRM) system when applied in manufacturing clothes , an industry which is directly related to the taste and preferences of the customer.

The figure shows the serial steps of applying (QRM) system :the customer contacts the manufacturing company either directly or through retail stores where a digital illustrates the size and dimensions of the customer is sent via communication networks to the manufacturing then this photo is transferred in to data fed to the modeling machine to cat and prepare the cloth which is sent eventually to a digitally controlled sewing machine. (Suri 2003:Al-Abaade 2005:34-36).

The delivery process according to the desire of customer starts instantly through a series of procedures beginning at the delivery center passing through the marketing and production processes and ending with the developing process. These procedures force each center to make drastic changes through reducing the time of the delivery cycle, and increasing the variety of products to meet the needs of customers, hence, this strategy is called (time based competitive). Obviously, relying on this strategy alone is not fruitful, unless integrating it with other strategies such as marketing within the framework of the value series, dividing the market into heterogeneous markets, increasing the variety of products, and(personality customization, provided that these strategies are applied by using the technologies of the Agile Factory (Pine,1993,189). 


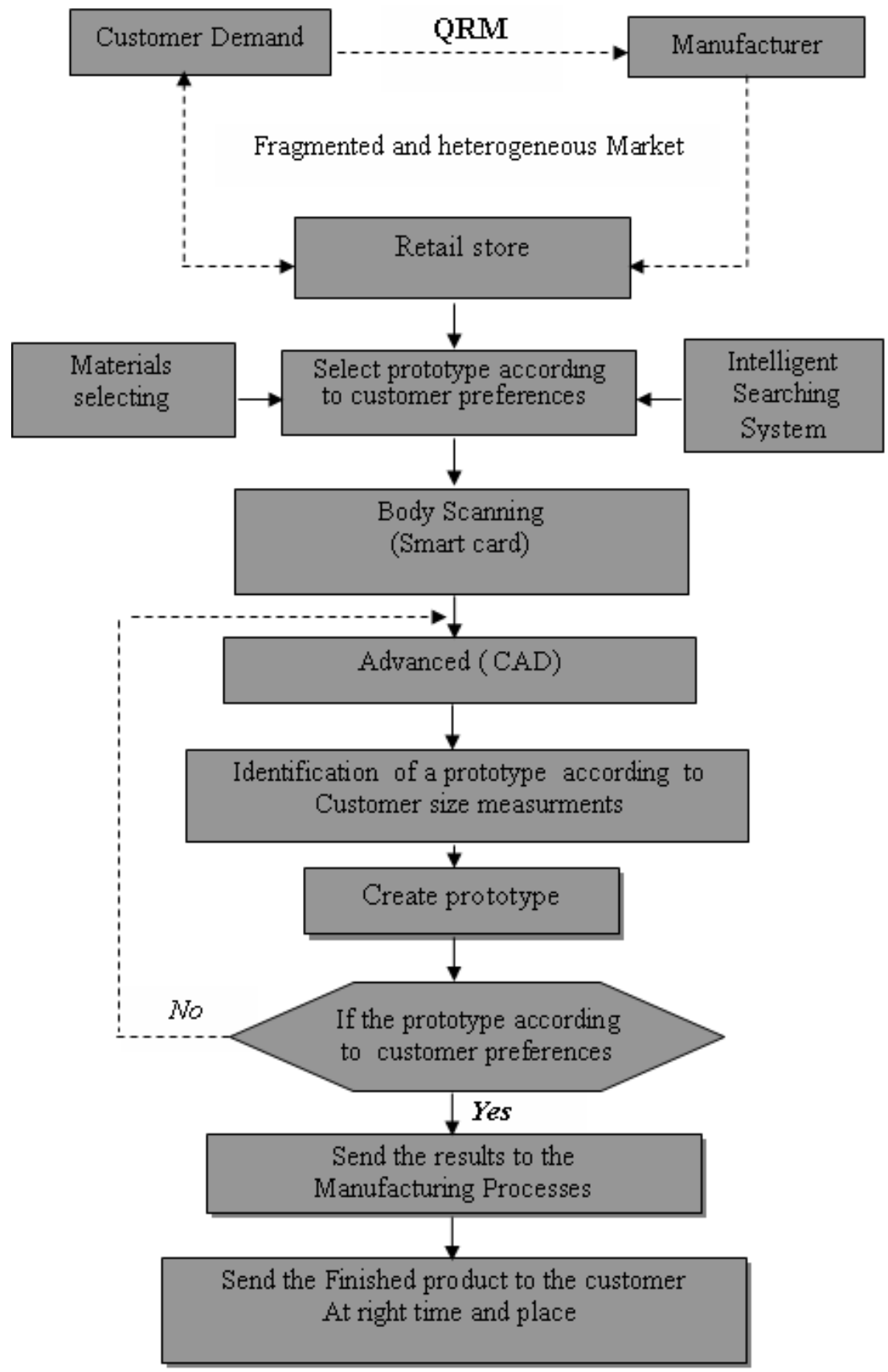

Figure(1): QRM Architecture

Source: Prepared by researchers depending on:

Lee, S., E., and chen, J. C., Mass Customization Methodology for Apparel Industry with future, Journal of Industrial technology, Vol. 16, No. 1, 1999. 


\section{Managing the Challenges of Engineering data}

High variety Production Like (QRM) is facing the challenge of effective variety management, which needs to deal with numerous variants of both produvt and process in order to accommodate diverse customer requirements. Traditional production management systems are often designed to support manufacturing based on a limited number of product variants. With the emerging trend of producing customized products to meet diverse customer needs, the number of product variants increases exponentially in QRM. In a situation of assembly to order production, production planning and control involve not only product variety, but also process variety .It is imperative to synchronize product and process variety in a coherent manner.(Du,2005,1; Jiao, 1999).

The challenges of data management associated with high variety production can observed as follows: (Jiao,2000,2-4) :

1. Data explosion : The traditional approach to variant handling is to treat every variant as a separate product by specifying a unique Bill-ofMaterials (BOM) for each variant. This works with a low number of variants but not when customers are granted a high degree of freedom for specifying products. The problem is that a large number of BOM structures will occur in mass customization production, in which a wide range of combinations of product features may result in millions of variants for a single product Design and maintenance of such a large number of complex data structures are difficult, if not impossible . to deal with a large number of variants, it is necessary to understand the implication of variety and to characterize variety effectively.

2. Data redundancy : The development of product families has been recognized as an effective means of supporting variety. Partial and complete descriptions of the structure of a product are created and utilized throughout the product development and innovation process. Product structures and associated coding systems are usually specific to particular product families, which results in large amounts of redundant product data. In order to minimize data redundancy, the representation of product families is different from traditional product modeling in that product data have to be related to both families of products and specific product variants in a single context .

3. Data comprehensiveness: Increasing variety has far reaching influence on many organizational functions such as sales and marketing, product engineering, and manufacturing. The commercial department is primarily engaged in processing customer specific orders, which involves final product configuration and quotations of cost and delivery time. Due to variety, engineering change control becomes a serious 
problem for the design department. It has been pointed that ( Manufacturing Resources Planning MRPII) has achieved only limited success in its industrial implementation and the shortfall is due to fundamental weakness of its planning logic ,that is, the lack of integration between (Metrial Requirement Planning) and (Capacity Requirements Planning)

4. Data separation: Traditionally, product Data management (PDM) technologies enhance the manageability of large amount of product data such as engineering documents and drawings, part lists and BOM. While (PDM) is engineering oriented and focuses on the product structure in the form of a BOM, production information management is operation -oriented and emphasizes the process structure in the form of routings . these two groups of data, together with work centers as capacity units, form the basic elements of the manufacturing process.

Towards this end, this paper tackles integrated product and production data management for (QRM) by high variety. A data structure, called Bill of Materials and Operations(BOMO), is proposed for the purpose of unifying BOM and Routings in order to facilitate better production planning and control, order processing, and engineering change control . To deal with variety effectively, the concept of a generic BOMO is put forward. A generic variety structure is also developed to characterize variety effectively. The merits of the generic BOMO far integrated product and production data management are detailed in terms of order processing, engineering change control, MRP, production job planning, costing, and capacity planning.

\section{Discussing the Results of Applying Software Designing in framework of (BOMO)}

Depending on the details of the software treatment designed by using the database (Oracle), the ideas and suggestions of (Jun Du, Yuan Jiao and Jianxin Jiao) as well as the practical addition suggested by the researchers of the current paper to serve adequately in the Iraqi environment, the current paper tackles primarily ${ }^{(1)}$ the algorithms which integrate the (Bill of Material) with the (Routing ) of the product family .

In order to point out the output results of the system which is designed depending on (BOMO) and discussing them appropriately, the current paper relies on collected data of a case study which is represented in a three-

(1) Due to the numerous details which associate the software treatment, the results of applying this treatment are divided into two individual papers, the first focuses on (GBOB) of the product category under discussion, while the second is this current paper. 
drawers desk, as an element from a product family consists of six individual products intended to be manufactured by the General Company for Manufacturing Furniture.

Depending on the (GBOM) of the product family which was formulated in a previous study, according to the designing software, the current paper focuses on:

1. Formulating (General Product Structure GPS) for the product family. The designing software are very flexible if used to design (GPS) . Fig (2) illustrates a form through which all the main and sub processes, required for producing certain products within a specific family, are identified. Similarly, the algorithm of (Structure of prod_family_routing Rep) represents the steps required for identifying the routing of the product family, which includes products that have similar routings in most processes . Yet, some products do not require all the processes identified by the routing of the product family, hence the general routing is divided into minor routing's through the field (Path), while in other families, only one routing is enough for all the products of the family .

The form illustrated in fig(2) contains fields to identify machines and processes required for manufacturing products of a certain family, as well as the preparation and treatment times for each process. In addition, the form also includes the procedure (Prod_family_Routing Rep) which identifies and executes the report associated with the routing .

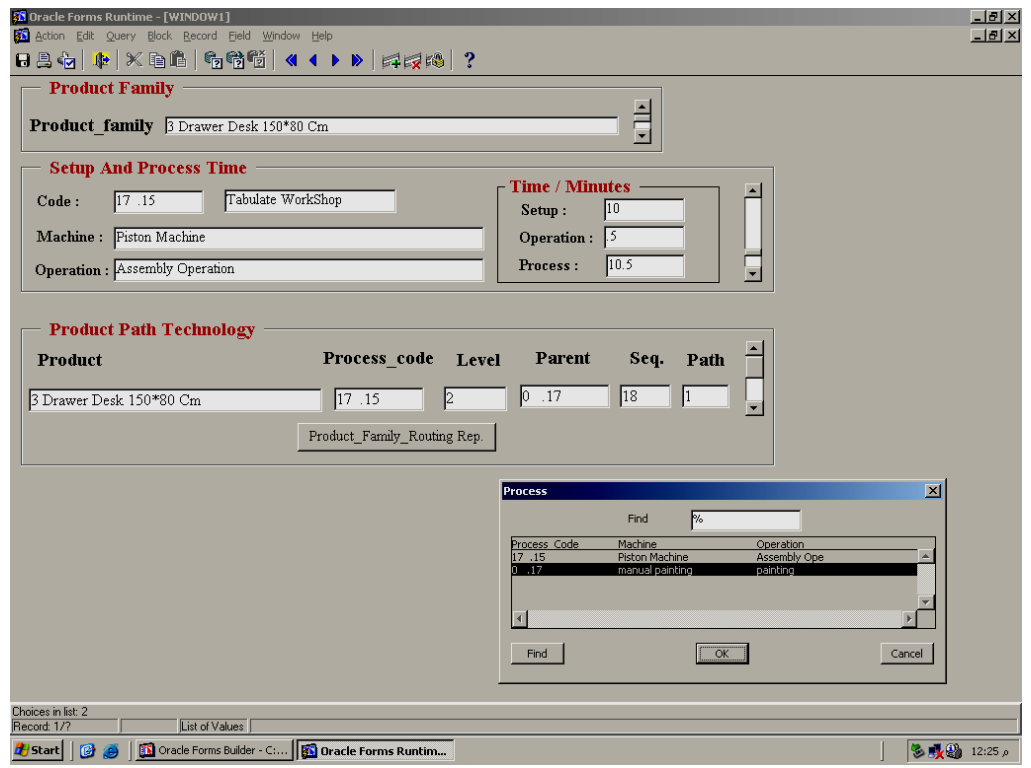

Figure (2) form for specified product Routing 
2. BOMO Formulation : the main idea in this structure is to make a link between (GPS) and (GBOM) as follows : After receiving the specifications of the product, according to the preferences of the customer, the designing software, simultaneously, create the (BOM) and identify the routing of the chosen product. Fig(3) illustrates a form through which the components of (BOM) and the processes of routing can be identified together, hence, the materials, components and sub assemblies are linked to the operation, not to the (Parent Product ) as is the case with traditional (BOM) .

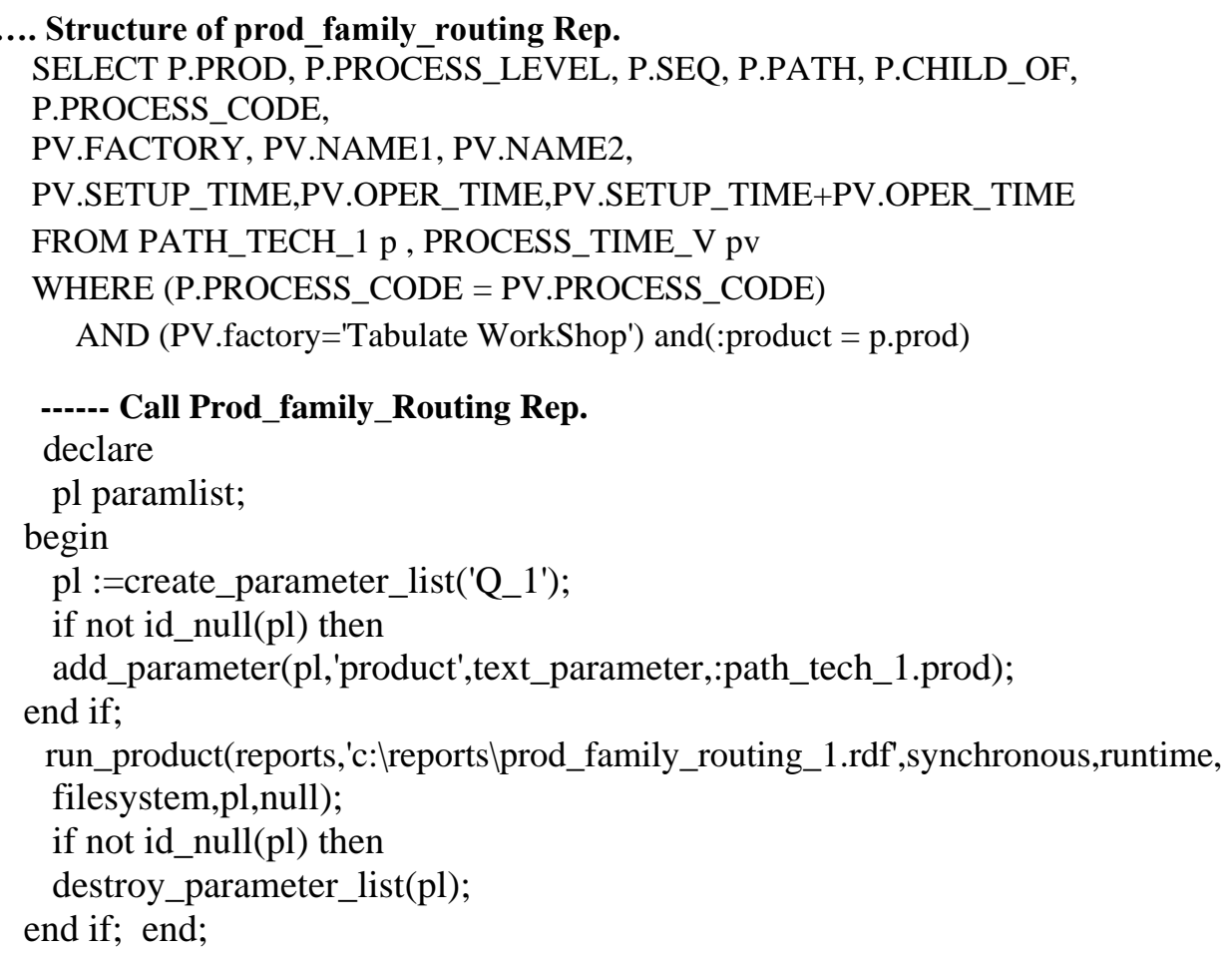




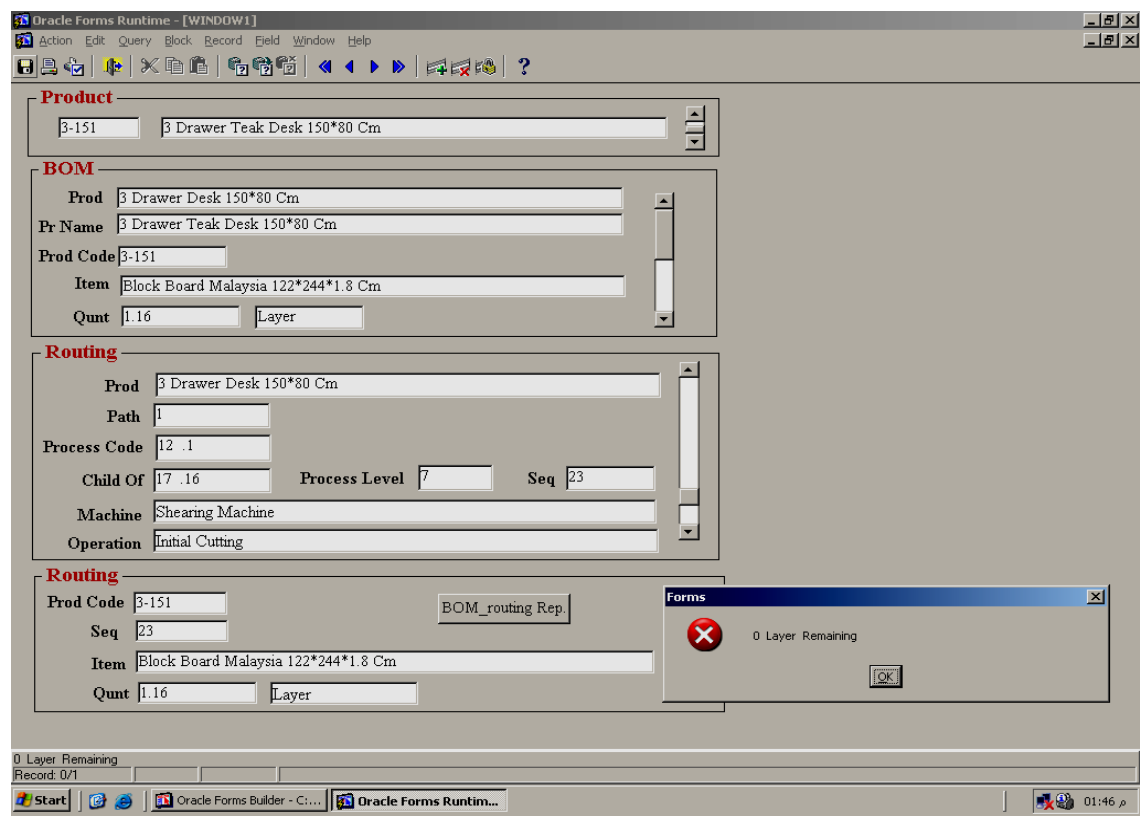

Figure (3) form through which BOMO determined for case study

Figure(3) also points out that the quantities, parts and components of the materials are calculated precisely at all levels of (GBOM), so, when higher quantities are identified, the customer is informed instantly. The algorithm (bom_routing_Rep structure ) illustrates the mechanism of linking and identifying the (GBOM) and the (Routing ) simultaneously. While the algorithm ( call bom_routing_Rep ) specifies a procedure to preview BOMO as a (Data Model) as shown in Table(1) . 
..... bom_routing_Rep. structure

SELECT :product || ' || pr.prod.item.name1 n, s.inventory.mes_unt, P.SETUP_TIME+p.oper_time,pr.prod.lead_time,B.SEQ,

nvl(B.ITEM,'subassemblies parts'), B.QUNT,

PT.PROCESS_LEVEL, PT.PROCESS_CODE, PT.CHILD_OF, P.NAME1, P.NAME2,

P.SETUP_TIME, p.oper_time

FROM BOM_ROUTING_1 b, PROCESS_TIME_V p, PATH_TECH pt, product pr, stock $\mathrm{s}$

WHERE $(($ B.SEQ $(+)=$ PT.SEQ $)$

AND (PT.PROCESS_CODE $=$ P.PROCESS_CODE)

AND (B.PROD_CODE $(+)=$ PT.PROD_CODE) and (pt.prod_code=:product)

AND pt.prod_code=pr.prod_code and pr.prod.factory $=$ p.factory

AND s.inventory.item.name1(+)=b.item)

order by pt.process_level desc

...... call bom_routing_Rep.

declare

pl paramlist;

begin

$\mathrm{pl}:=$ create parameter_list('Q 1 ')

if not id_null( $\mathrm{pl})$ then

add_parameter(pl,'product',text_parameter,:bom_routing_1.prod_code); end if;

run_product(reports,'c:|reportslbom_routing_1.rdf',synchronous,runtime,filesys tem,pl,null);

if not id_null(pl) then end if;

destroy_parameter_list(pl);

end;

Table(1) parameters

:product : product code

Pr.prod.item.name1 : product name

s.inventory.mes_unt : products measure unit

b.item : raw material

b.qunt : raw materials quantity

p.setup_time : setup time

p.oper_time : process time of machine

pr.prod.lead_time : products lead time

pt.process_level : machine routing level

p.name1 : machine name

p.name 2 : operation name

$\mathrm{b}, \mathrm{p}, \ldots$ etc $:$ alias names of bom_routing_1 table and process_time_v view sequencially

pr.prod.factory : factory name 
So, the synchronizing between the data of the product in (BOMO) which describes the final product and all its components, and the product information in routing, contributes to a high extent in reducing deadlines according to the method of (QRM) .

3. Table (1) describe the logic of BOMO )processing : BOM link each component materials directly with its parent product, BOMO link a component materials with the relevant operation in the BOO for producing its parent component. For each subassembly or end product, a single- level BOMO structure can be derived by specifying the sequence of operations required for producing that product as well as materials and resources required for each operation.

The multi-level BOMO can be composed by linking the single-level BOMOs of lower-level intermediate parts through the operations that require them. Data Model in Table (1) referred to as Bill of Materials and Operations(BOMO), can developed by linking the BOM structure with BOO structure in to a single one . BOMO structure Specifies the sequence of production operations required for making an intermediate part subassembly or end product as well as materials and resources required at each operation.

4. The results shown in Table (1) and fig(4) reveal that (BOMO ) includes preparing processes called (Kitting), which may accompany or preceed all the processes of production or assembling. The data in Table(1) confirm that the preparation processes are not required only for materials, parts and minor assemblies, but also for preparation the production facilities. Its important to indicate that the (operations with same sequence number indicate parallel operations) .

Table (1) reveal also that the designed system adopted object-oriented data model, so the indirect identification of variants from a generic product through variety parameters and their values conforms to the class member relationship of object oriented concept . Three classes of objects belong to subclasses of the root class, a product object represents the super class of subclasses that defines a specific constituent item . Its major subclasses might be component, subassembly and product object class. A process object represents the super class of subclasses that defines the operations routings of constituent items. 
Table (1) BOMO Data for 3 Drawer Desk

\begin{tabular}{|c|c|c|c|c|c|c|c|}
\hline $\begin{array}{l}\text { Seq. } \\
\text { No. } \\
\end{array}$ & Operation & $\begin{array}{l}\text { Work } \\
\text { Center } \\
\end{array}$ & $\begin{array}{l}\text { Run } \\
\text { time } \\
\end{array}$ & $\begin{array}{l}\text { Material } \\
\text { Component }\end{array}$ & \begin{tabular}{|l} 
Product \\
Parent Item \\
\end{tabular} & Qunt. & \\
\hline 160 & Painting (A4) & Wc-A4 & 90 & \multirow{2}{*}{$\begin{array}{l}\text { Subassembly } 14 \\
\text { Cotton } \\
\text { Damalock } \\
\text { Spirit } \\
\text { Dough }\end{array}$} & \multirow[b]{2}{*}{ 3drawer desk } & 1 & No \\
\hline 150 & Kitting (K20) & Wc- k20 & 5 & & & $\begin{array}{l}.1 \\
.2 \\
.2 \\
.03\end{array}$ & $\begin{array}{c}\mathrm{Kg} \\
\mathrm{Kg} \\
\text { Liter } \\
\mathrm{kg}\end{array}$ \\
\hline 140 & Assembly ( M2) & Wc- M2 & .5 & \multirow{2}{*}{ Subassembly 13} & \multirow[b]{2}{*}{ Subassembly14 } & \multirow[b]{2}{*}{1} & \multirow[b]{2}{*}{ No } \\
\hline 130 & Kitting( K19) & Wc- k19 & 10 & & & & \\
\hline 120 & Thermal Glue (M5) & Wc- M5 & 25 & \multirow{2}{*}{$\begin{array}{l}\text { Drawers } \\
\text { Desk top } \\
\text { Sides structure }\end{array}$} & \multirow[b]{2}{*}{ Subassembly13 } & \multirow[b]{2}{*}{$\begin{array}{l}3 \\
1 \\
3\end{array}$} & \multirow[b]{2}{*}{$\begin{array}{l}\text { No } \\
\text { No } \\
\text { No }\end{array}$} \\
\hline 110 & Kitting K18 & Wc- k18 & 10 & & & & \\
\hline 100 & Assembly (A2) & Wc- A2 & 1 & \multirow{2}{*}{$\begin{array}{l}\text { Subassembly } 12 \\
\text { Golden Handle } \\
\text { Nail } 25 \mathrm{~mm} \\
\text { Switch } \\
\end{array}$} & \multirow[b]{2}{*}{ Drawers } & 1 & No \\
\hline 90 & Kitting K16 & Wc- k16 & 10 & & & $\begin{array}{l}1 \\
3 \\
1\end{array}$ & $\begin{array}{l}\text { No } \\
\text { No } \\
\text { No }\end{array}$ \\
\hline 100 & Assembly (A3) & $\mathrm{Wc}-\mathrm{A} 3$ & 1 & \multirow{2}{*}{$\begin{array}{l}\text { Sides } \\
\text { Base Sides }\end{array}$} & \multirow{2}{*}{ Sides Structure } & 1 & No \\
\hline 90 & Kitting K17 & Wc-k17 & 10 & & & 1 & No \\
\hline 80 & Thermal Glue (M5) & $\mathrm{Wc}-\mathrm{M} 5$ & .5 & \multirow{2}{*}{ Subassembly 9} & \multirow{2}{*}{ Subassembly 12} & 1 & No \\
\hline 70 & Kitting K13 & Wc- k13 & 10 & & & 1 & No \\
\hline 80 & Holing ( M4 ) & Wc-M4 & .5 & \multirow{3}{*}{$\begin{array}{l}\text { Subassembly } 11 \\
\text { Subassembly } 10\end{array}$} & \multirow{3}{*}{$\begin{array}{l}\text { Sides } \\
\text { Desktop }\end{array}$} & 1 & No \\
\hline 70 & Kitting K15 & Wc- k15 & 10 & & & 1 & No \\
\hline 70 & Kitting K14 & Wc- k14 & 10 & & & 1 & No \\
\hline 60 & Scratching (M3) & Wc- M3 & 1 & \multirow{5}{*}{$\begin{array}{l}\text { Subassembly } 5 \\
\text { Subassembly } 6 \\
\text { Subassembly } 7 \\
\text { Subassembly } 8\end{array}$} & \multirow{5}{*}{$\begin{array}{l}\text { Base Side } \\
\text { Subassembly11 } \\
\text { Subassembly10 } \\
\text { Subassembly9 }\end{array}$} & 1 & No \\
\hline 50 & Kitting K12 & Wc- k12 & 10 & & & 1 & No \\
\hline 50 & Kitting K11 & Wc- k11 & 10 & & & 1 & No \\
\hline 50 & Kitting K10 & Wc- k10 & 10 & & & 1 & No \\
\hline 50 & Kitting K9 & Wc-k9 & 10 & & & 1 & No \\
\hline 40 & Cold Pressure (M2) & Wc- M2 & 360 & \multirow{4}{*}{$\begin{array}{l}\text { Subassembly } 3 \\
\text { Subassembly } 2 \\
\text { Subassembly } 1\end{array}$} & \multirow{4}{*}{$\begin{array}{l}\text { Subassembly } 6 \\
\text { Subassembly } 7 \\
\text { Subassembly } 8\end{array}$} & 1 & No \\
\hline 30 & Kitting K7 & Wc-k7 & 10 & & & 1 & No \\
\hline 30 & Kitting K6 & Wc-k6 & 10 & & & 1 & No \\
\hline 30 & Kitting K5 & Wc- k5 & 10 & & & 1 & No \\
\hline 40 & Slicing ( M6 ) & Wc- M6 & .5 & \multirow{2}{*}{ Subassembly 4} & \multirow{2}{*}{ Subassembly 5} & 1 & No \\
\hline 30 & Kitting K8 & Wc-k3 & 5 & & & 1 & No \\
\hline 20 & Single Saw (A1) & Wc- A1 & 5 & \multirow{2}{*}{ Mahogany } & \multirow{2}{*}{ Subassembly 4} & \multirow{2}{*}{.1} & \multirow{2}{*}{ Cube } \\
\hline 10 & Kitting K4 & $\mathrm{Wc}-\mathrm{k} 4$ & 5 & & & & \\
\hline 20 & Initial Cutting (M1) & Wc-M1 & 3 & \multirow{4}{*}{$\begin{array}{l}\text { Banal } \\
\text { Block Board } \\
\text { Teak }\end{array}$} & & & \\
\hline 10 & Kitting K3 & Wc- k3 & 10 & & Subassembly 1 & .22 & Layer \\
\hline 10 & Kitting K2 & Wc- k2 & 10 & & Subassembly 3 & $\begin{array}{l}1.10 \\
1.16\end{array}$ & $\begin{array}{l}\text { Layer } \\
\text { Layer }\end{array}$ \\
\hline 10 & Kitting K1 & Wc-k1 & 10 & & & & \\
\hline
\end{tabular}




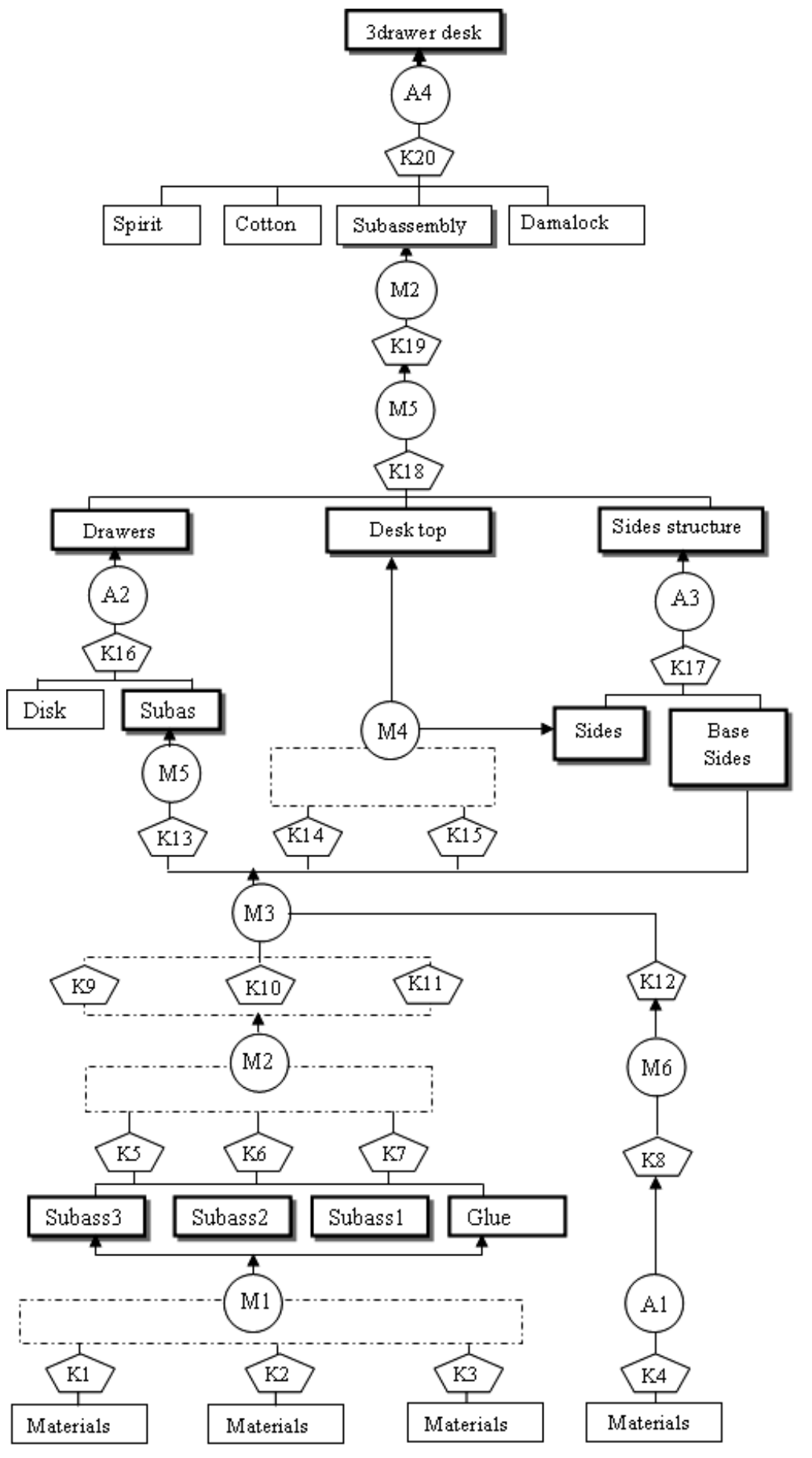

Figure (4) BOMO For 3 drawer disk

Sources: Prepared by researchers 


\section{Conclusions}

The main aim of the current paper is to focus on (BOMO) approach and the results obtained when applying it practically to a real product, as a part of the designing software to support the mechanisms of designing and manufacturing according to (QRM) . Thus, the main conclusions of the current paper, which agree with its aims, can be listed as follows :

1. The results confirmed that (BOMO structure) combines both product data and operation information set to tackle these data and information synchronize, which, doubtless, provides the possibility to perform the process parallel, and reducing waiting time between processes, and reducing deadlines eventually.

2. The results shown in Table (1) confirm that row materials, parts, and components are not associated to the parent product at the higher level of (BOMO), according to the logic of treatment by (MRP) system. While (BOMO) associates a component material with the relevant operation in to Bill of operation for producing its parent component.

3. Although the Kitting process is widely used in industry to convert the internal setup as possible into the external setup in order to reduce setup cost, which constitutes a large proportion of the overall cost of assembly . The results shown in Table (1) that the concept of kitting has been extended to include not only component parts but also tools and fixtures. So, this certainly reducing product lead time .

4. The results show that the designing software, specifically (BOMO) structure, can be a good incarnation for the (QRM) processing logic , through synchronize designing and manufacturing processes instead of tackling (BOM) and (Routing) individually, hence, reducing the product lead time .

5. The results explain that, the BOMO structure provide flexibility in handling relationships between materials and operations in response to diverse customer needs and preferences. 


\section{REFERENCES}

[1] Al-Abaade,S.S.,Quick Response Manufacturing System and Horizons of its Application, thesis submitted to College of Administration and Economic, University of Mosul,2005.

[2] Du,X. , Jiao,J.and Tseng, M.M. Architecture of Product Family: fundamentals and Methodology. Concurrent Engineering : Researh and Application, Vol.9.No.4, 2001.

[3] Du,X.; Jiao,J.; Tseng, M.M., Product family modeling and design Support, AIEDAM, Vol.16,No.2,2002.

[4] Du,X.; Jiao,J. Integrated BOM and Routing generator for Variety Syncronization in Assembly to - order production, Journal of Manufacturing Technology Management, Vol.16,No.2,2005.

[5] Evans, J.R., Applied Production and Operation Management, West Publishing, 1997.

[6] Jainis, S., and Farm, B., Gain A competitive A dvantage with Quick Response, Lowa Textile and Apparel Industry News, Vol.2, No.4, 1997.

[7] Jiao,J.;Tseng,M.M., An Information modeling framework for product families to support mass customization production, Annals of CIRP, Vol.48,1999.

[8] Jiao,J.;Tseng,M.M., Zou,Y., Generic Bill-of-Materials and Operations For High-Variety production Management, concurrent engineering: Research and Application, Vol.8,No.4, 2000 .

[9] Lee, S., E., and chen, J. C., Mass Customization Methology for Apparel Industry with future, Journal of Industrial technology, Vol. 16, No. 1, 1999.

[10] Lindsay,H., and Stratagem, M., QRM: An Enabler on the Road to Agility, Control , May,2002.

[11] Pine II and Joseph, B., Mass Customization, the new frontier in Business Competion, Harvard Business School Press.

[12] Russell,.R.S., Taylor,R.W., Operation Management Focusing on Quality and Compositeness, Printic Haill,1998. 
[13] Suri, R, Quick Response Manufacturing : A competitive Strategy for the 21 st century , Proceedings of the 2002, POLCA implementing workshop, center of Quick response Manufacturing.

[14] Suri, R, Quick Response Manufacturing : A company wide Approach to Reducing lead times, Productivity Press, Portland, 1998.

[15] Suri,R., QRM and Polca : A wining combination for Manufacturing Enterprises in the 2 Ist century, Technical Report center for Quick Response Manufacturing, 2003.

[16] Tubino, F., Suri, R., Quick Response Manufacturing , Advanced Manufacturing 2001.

[17] Turner,T.,and others, Quick Response Manufacturing : when Kanban is not the solution ,Journal of Control, No.2, 2006 